\title{
Diagnostic Endoscopic Ultrasound of the Pancreas May Cause Acute Pancreatitis
}

Acute pancreatitis is a well-known complication of endoscopic retrograde cholangiopancreatography (ERCP) (1), and has been described after endoscopic ultrasound (EUS)-guided pancreatic fine-needle aspiration (FNA) (2). It has not been reported in association with purely diagnostic pancreatic EUS.

A 22-year-old woman with recurrent acute pancreatitis was referred to EUS and ERCP. She had a ten-year history of intermittent epigastric pain radiating to the back, associated with nausea and vomiting. The patient had been hospitalized on three occasions in the previous three years (most recently four months before) with similar acute pain and elevated amylase and lipase levels. Attacks of epigastric pain continued after a laparoscopic cholecystectomy was performed for cholelithiasis two years before. The patient denied ever consuming alcohol, and there was no family history of pancreatitis. Calcium and triglyceride levels were normal. Immediately before EUS, the patient was asymptomatic, amylase and lipase levels were normal, and the white blood cell count (WBC) was $5800 / \mathrm{mm}^{3}$. Diagnostic pancreatic EUS was performed under conscious sedation (midazolam $1.5 \mathrm{mg}$, meperidine $75 \mathrm{mg}$ ) without difficulty. The procedure lasted 22 minutes.
The uncinate process was examined from the second portion of the duodenum, the head from the apex of the duodenal bulb, and the body and tail from the mid-body of the stomach. EUS suggested chronic pancreatitis, showing echogenic foci and an irregular, hyperechoic main pancreatic duct margin (3). The pancreatic duct appeared bifid in the head (Figure 1). FNA was not attempted. Within 30 minutes after EUS, the patient complained of new-onset increasing epigastric pain. An abdominal flat plate showed no free air. Three hours after EUS, amylase was three times normal, lipase 12 times normal, and the WBC was $11700 / \mathrm{mm}^{3}$. The patient was hospitalized, and responded well to intravenous fluids and analgesics. All symptoms and laboratory test abnormalities gradually resolved within 48 hours. ERCP and sphincter of Oddi manometry performed at this time were normal, except for an ansa pancreatica (Figure 2). Deep cannulation of the pancreatic duct for pancreatic manometry was not possible. No post-ERCP pancreatitis occurred.

In this case, acute pancreatitis may have been induced by mechanical irritation of the gland, in a patient with a demonstrated predisposition for acute pancreatitis, possibly due to the presence of an ansa pancrea-

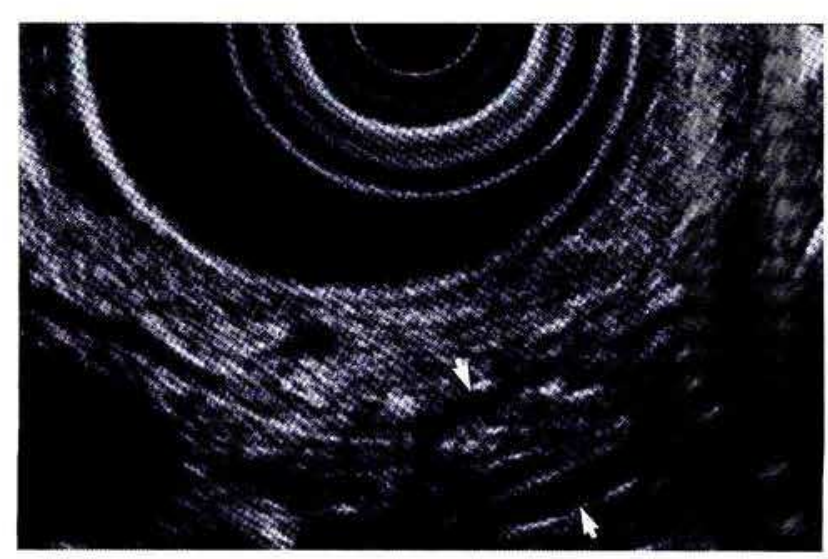

Figure 1: On EUS, the pancreatic duct appears bifid (arrows) in the head of the gland. 


\section{Unusual Cases and Technical Notes}

tica (4). Acute pancreatitis should be regarded as a possible complication of diagnostic pancreatic EUS, and should be included in the differential diagnosis of post-procedural abdominal pain.

D. Kulling, A. V. Sahai, W. L. Knapple, J. T. Cunningham, B. J. Hoffman

Digestive Disease Center,

Medical University of South Carolina,

Charleston, South Carolina, USA

\section{References}

1. Sherman S, Lehman GA. ERCP- and endoscopic sphincterotomy-induced pancreatitis. Pancreas 1991; 6: 350-67.

2. Gress FG, Hawes RH, Savides TJ, et al. Endoscopic ultrasound-guided fineneedle aspiration biopsy using linear array and radial scanning endosonography. Gastrointest Endosc 1997; 45: 243-50.

3. Wiersema MJ, Hawes RH, Lehman $\mathrm{GA}$, et al. Prospective evaluation of endoscopic ultrasonography and endoscopic retrograde cholangiopancreatography in patients with chronic abdominal pain of suspected pancreatic origin. Endoscopy 1993; 25: 555-64.

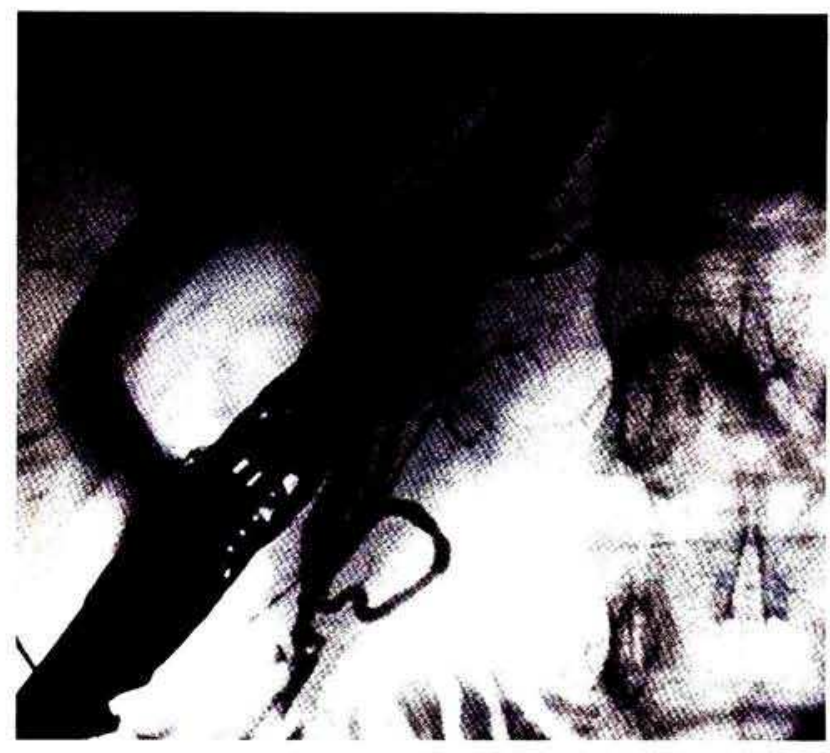

Figure 2: $E R C P$, showing an ansa pancreatica.
4. Tanaka T, Ichiba Y, Miura Y, et al. Variations of the pancreatic ducts as a cause of chronic alcoholic pancreatitis: ansa pancreatica. Am J Gastroenterol 1992; 87: 806 .
Corresponding Author

D. Kulling, M.D.

Digestive Disease Center

Medical University of South Carolina

171 Ashley Avenue

Charleston, SC, 29425, USA

Fax: + 1-803-792-4184 